\title{
A new Photometer
}

This content has been downloaded from IOPscience. Please scroll down to see the full text. 1882 Proc. Phys. Soc. London 5253

(http://iopscience.iop.org/1478-7814/5/1/330)

View the table of contents for this issue, or go to the journal homepage for more

Download details:

IP Address: 131.94.16.10

This content was downloaded on 08/09/2015 at 07:31

Please note that terms and conditions apply. 
Substituting for $a$ and giving $n$ the values $0,1,2,3, \& c$. in order, we can obtain values for $i_{0}, x_{1}, x_{2}$ \&c., and determine thus the position of the lines. A plane grating ruled in this manner would form at $Q_{1}$ without aberration an image of $Q$ for light of the given wave-length $\lambda$. Of course it would be open to the objection which holds against all such aplanatic arrangements, viz. that they are only good for light of one definite wave-length. If the grating were used for light of a different refrangibility, the image formed would suffer from aborration.

\section{A new Plotometer. $B y$ Sir John Coxroy, Bart., M.A.*}

Ilaving recently made a considerable number of photometric observations, and learnt by experience the difficulty which attends all such determinations, I venture to bring before the Soriety the description of a new form of photometer which aplears to possoss certain advantages over those in use. All such instruments, with the execption of the wedre-photometer, are essentially arrangements for comparing the illaminating-power of two lights, and therefore do not give alssolute measures; the one I propose describing is no exception to this general rule.

I lad intended to use, in some experiments on the amount of light reffected by metallic surfaces, the ordinary Bunsen's disk; but I found that, owing to the small size of the bosm of reffected light, it was impossible to make any satisfactory measurements with the disks in common use, and after trying various photometric arrangements I finally adopted a moditiaation of Ritchie's photoncter.

The various forms of shadow-photometers work well; but as the accuracy of the determination depends on the edge of the two shadows coinciding and yet not overlapping, it is necessary to have some arrangement for altering the distance between the screen and the shadow-producer, which adds to the complexity of the apparatus, except indeed when, as in Mr. Harcourt's photometer for gas-work, the variation in the relative intensities of the two lights is caused by the size of one of the flames being altered, and not, as in those arringe-

* Read April 28, 188:3. 
ments heretofore in use, by altering the distance of the flame from the screen whilst the size is kept constant.

Ritchie's photometer, as is well known, consists of two pieces of white paper fastened to the adjacent sides of a triangular block of wood, each being illuminated by one only of the lights which are to be compared. Finding it impossible so to arrange the apparatus that the illuminated surfices should be actually in contact, the bend in the paper along the edge of the block separating the two illuminated arens, and therefore interfering with the accuracy of the determination, I placed one of the pieces of paper slightly in front of the other, and overlapping it to a small extent, so that, whilst both were visible to the observer, each was illuminated by one only of the sources of light; when equally illuminated, the edge of the front paper vanished.

It was originally intended that the light should be incident npon the surfaces of the paper at an angle of $45^{\circ}$; but it was found that when the light regularly reflected by the paper reached the observer ( $i$. e. when the line of sight and the direction of the incident light formed equal angles with the normal to the paper) it was not possible to make satisfactory measurements.

After varions positions had been tried, it was found that the best results were obtained when the light was incident upon the paper at an angle of about $30^{\circ}$ and the line of sight formed an angle of $60^{\circ}$ with the normal.

Two triangular blocks of wood, 4 centim. high, were screwed to a rectangular board about 15 centim. by 10 centim., in the position shown in the figure, and pieces of white paper, 3 centim. by 3 centim. (filter-paper was tried ; but ordinary white writing-paper not too highly glazed seemed most suitable), held against the hypotenuse of each of the triangular prisms by india-rubber. bands.

It is of course essential that the light should be incident upon both papers at equal angles, and that the papers should be so placed that no light chn

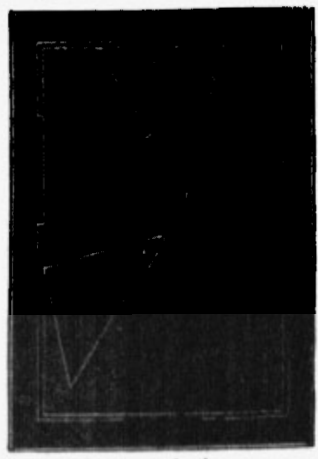

$\frac{1}{4}$ actual size. 
be reflected from one to the other. It is desirable that both papers should be cut from the same sheet, and that the surfaces on which the light is incident should originally have formed one side of that sheet.

A rectangular board, similar to that to which the prisms were fixed, was fastened to the top of the prisms by two screws; and to the edges of this board four strips of card, in three of which square apertures had been cut, were fixed, and the whole arrangement painted both externally and internally a dead black.

In order to adjust the papers, or replace them by new ones, it is merely necessary to withdraw the two screws in the. top board and lift it off, together with the sides of the box.

The edge of the front paper coinciding with the middle line of the box, the photometer could be used with either side uppermost; and in order to be certain that the illumination of both papers was entirely due to light incident directly upon them, measurements of the relative intensity of two similar paraffin-lamps were made with the photometer in both positions; and it was found that the readings were identical.

The photometer was compared with a Bunsen's disk by placing it at the end of a horizontal board furnished with a scale, and along which a paraffin-lamp was arranged to slide. A Bunsen's disk, in an ordinary form of support with two inclined looking-glasses, could be screwed to the end of the board, to which three stops were so fixed that, when the disk was removed and the new photometer placed against the stops, the middle line of the box was in the same vertical plane as the disk had been.

A paraffin-lamp was placed on either side of the photometer, the position of one remaining constant, whilst that of the other was altered until the illumination was equal, and the distance of the latter read off, in centimetres, on the scale.

The table gives the results of eight observations made with both photometers, the differences of each observation from tho mean, and also the squares of these differencer. 


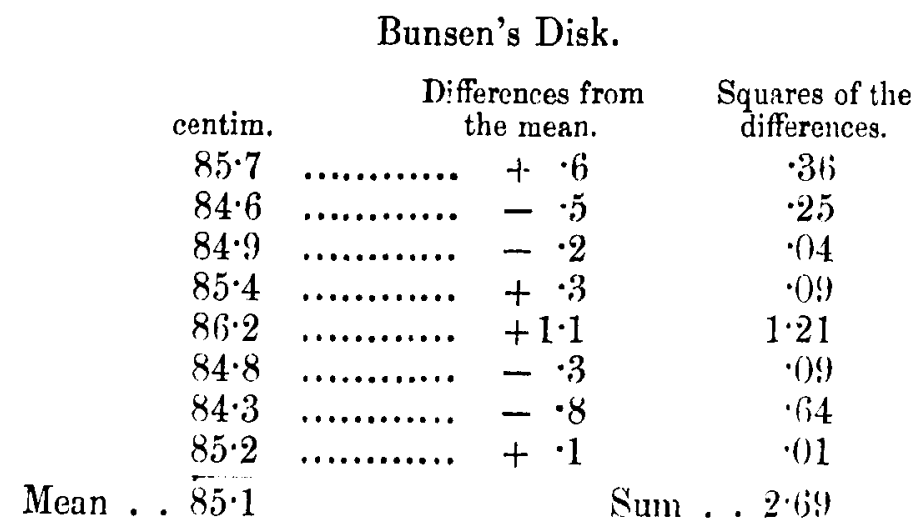

New Photometer.

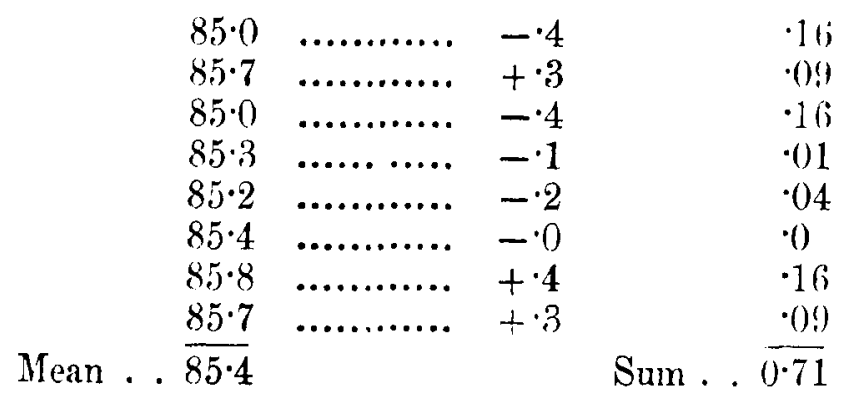

The probable error of the mean result and the probable error of a single observation were found by the ordinary formula, $0.6745 \sqrt{\text { sum of the squares of the differences }} \frac{\text { and }}{n(n-1)}$. probable error of the mean result, $n$ being the number of observations.
Bunsen's Now disk. photometer. centim. centim.
Probable error of mean result ..... $\pm 0.148 \pm 0.076$
" $" \quad$ single observation $\pm 0.418 \quad \pm(0 \cdot 215$

The new photometer therefore appears to be twice as accurate as the Bunsen's disk : it is only fair to add that, had the measurements been made by an observer accustomed to work with the disk, the result might have been different. 